\title{
Diferenças culturais percebidas por brasileiros no uso da língua inglesa no exterior e seu tratamento em livros didáticos
}

\section{Cultural Differences in the Use of English as Perceived by Brazilians Living Abroad and their Treatment in Textbooks}

\author{
Alessandra Sartori Nogueira* \\ Universidade Estadual de Campinas \\ Campinas - São Paulo / Brasil
}

RESUMO: Apostando na inseparabilidade entre língua e cultura, o presente estudo tem por objetivo explorar um recorte dessa relação a partir de relatos sobre conflitos culturais vividos por brasileiros em países de língua inglesa. São aqui explorados quatro de sete questionários obtidos, aqueles cujos respondentes relacionaram cultura a questôes linguísticas como pronúncia, entonação, gramática e vocabulário, algo que era inesperado. Em seguida, selecionamos em alguns livros didáticos as categorias linguísticas abordadas pelos respondentes, a fim de verificar se há aspectos culturais envolvidos no modo como essas questôes linguísticas são tratadas. Os resultados sugerem instâncias em que a relação língua-cultura pode ser materializada e explorada em sala de aula quando do ensino de estruturas linguísticas e pronúncia.

PALAVRAS-CHAVE: ILE; cultura; identidade; livro didático.

ABSTRACT: That language and culture are inseparable is broadly accepted in the field of language teaching. This study was thus designed to explore the relation between language and culture by examining anecdotes involving cultural conflicts collected from Brazilians in an English-speaking country. Here we analyze four (out of seven) questionnaires, for which respondent answers unexpectedly related culture to linguistic issues, such as pronunciation, intonation, grammar, and vocabulary. We then selected, from some textbooks, the linguistic categories detected in the anecdotes, aiming to verify whether there are cultural aspects involved in the way these linguistic issues are presented. Our results suggest how the inseparability of language and culture could be explored in classroom when teaching language structure and pronunciation.

KEYWORDS: EFL; culture; identity; textbook.

*alesartori@yahoo.com 


\section{Introdução}

A inseparabilidade entre língua e cultura já é bastante discutida e amplamente aceita (por exemplo, DAMEN, 1987; KRAMSCH, 1996; 1998; 2011). Apostando nesse conceito, o presente estudo ${ }^{1}$ tem por objetivo explorar um recorte dessa relação entre língua e cultura a partir de relatos sobre conflitos culturais vividos por brasileiros em países de língua inglesa. Quatro de sete questionários obtidos nos chamou especial atenção por terem seus respondentes relacionado cultura com questôes linguísticas, tais como pronúncia, entonação, gramática e vocabulário, o que não era esperado. Esses participantes relatam situaçóes em que foram mal interpretados e/ou considerados rudes pela forma linguística utilizada em algumas interações. Eles perceberam que os recursos linguísticos em português para expressar polidez não são os mesmos recursos utilizados em inglês. Algo que antes parecia insignificante gerou mal-entendidos a ponto de serem considerados rudes. Esses são, portanto, exemplos relevantes de que a forma é veículo de significado, o que é foco deste estudo. Como a análise é feita a partir dos relatos dos respondentes, o recorte na questão cultural a ser comentada na análise dos dados acaba sendo principalmente a polidez intercultural, componente mais comentado pelos respondentes.

Depois de obtidos os questionários, selecionamos em alguns livros didáticos (LDs) - utilizados em escolas de idiomas - as categorias linguísticas abordadas pelos respondentes, a fim de verificar se há aspectos culturais envolvidos no modo como essas questões linguísticas são tratadas. Essa comparação permite entender qual o conceito de língua-cultura mais comumente veiculado nas atividades linguísticas dos LDs em contraposição ao conceito de língua-cultura que demonstram ter os sujeitos desta pesquisa.

Os relatos sobre conflitos culturais se mostram essenciais, não só por evidenciarem conceitos sobre cultura já trazidos pelos sujeitos, mas também por serem a materialização discursiva do momento em que tais sujeitos movimentam-se entre as culturas. Este movimentar-se entre as culturas caracteriza-se por aquilo que Claire Kramsch (1996) denomina terceiro lugar

\footnotetext{
${ }^{1}$ Agradeço às professoras Dras. Terezinha de Jesus Machado Maher (Unicamp) e Linda Gentry El-Dash (Unicamp) pela leitura crítica do manuscrito. Agradeço às professoras Ana Luiza Teixeira Armentano e Leila Guaracy Peres Taves pelo empréstimo dos livros didáticos. Agradeço aos voluntários que responderam o questionário. Agradeço aos revisores anônimos pelas críticas e sugestôes.
} 
(third places) e Homi K. Bhabha (citado por SANTOS, 2004), terceiro espaço ou entrelugar (in-between). É neste terceiro lugar que o bilíngue funciona (MAHER, 2007b), sendo-nos, portanto, este conceito de suma importância.

Numa revisão do termo third places, Kramsch (2011), considerandoo rígido demais por aludir a um espaço estático, sugere o termo competência simbólica. Segundo a autora, o que é necessário em interações multilíngues não é somente uma competência comunicativa de falantes não nativos, mas sim uma competência mais sofisticada, que os auxilie a posicionarem-se no mundo e a encontrarem um lugar no mercado global das trocas simbólicas (KRAMSCH, 2006). Esclarece a autora que, enquanto a competência comunicativa tem foco no significado, a competência simbólica considera a forma como veículo de significado (KRAMSCH, 2006). Veremos nas nossas análises como nos é primordial esse novo olhar, que integra forma e significado.

Mesmo consciente da revisão do termo terceiro lugar, aqui continuaremos fazendo referência a ele, como também a entrelugar e terceiro espaço, por refletirem satisfatoriamente nossa visão de espaço discursivo. Por ser um lugar de movimento entre as culturas, aqui não o consideramos rígido e estático, mas fluido. Acreditamos ser a competência simbólica o resultado positivo dos conflitos que se materializam no terceiro espaço.

Isso posto, consideramos ser este "lugar" um espaço discursivo de trânsito entre as culturas, mostrando-se um aspecto rico para se explorar na sala de aula. É o espaço onde os conflitos acontecem, onde significados antes considerados fixos são questionados, onde as identidades são abaladas. É considerado por Maria Inês Pagliarini Cox e Ana Antônia de Assis-Peterson (2007) um lugar de transculturalidade por ser um processo pelo qual passam os sujeitos, transitando lá e cá, sem perderem sua cultura.

Os conflitos resultantes das interaçōes e negociaçōes entre os atores sociais iam para a lixeira da Linguística em seus primórdios e hoje se tornam objeto de estudo para entender o funcionamento das línguas (COX; ASSISPETERSON, 2007). E não é diferente para este estudo, que busca estudar momentos em que duas línguas entram em conflito, num recorte que evidencie o funcionamento de ambas. Por isso, esse espaço de conflitos é o ponto de partida para grande parte de nossa análise.

O terceiro espaço no qual transitam nossos sujeitos são materializados pelos seus relatos e analisados aqui; essas análises, como contribuição para a Linguística Aplicada, levam a sugestão aos professores de explorarem o terceiro espaço possível nas aulas, os espaços onde transitariam seus alunos. 


\section{Conceito de cultura e a questão da identidade}

A Modernidade contribuiu para o conceito elitista de cultura, aquele conhecido como "apanágio dos homens e das sociedades superiores" (VEIGANETO, 2003, p. 9). Nos anos 20 do século passado, a antropologia, a linguística e a filosofia começaram a questionar tal conceito, seguidas mais tarde da Sociologia, Politicologia e Estudos Culturais (VEIGA-NETO, 2003). Como resultado, temos que, na pós-modernidade, cultura passa a ser entendida como sistemas partilhados de significação usados para classificar o mundo, dar sentido ao mundo social e construir significados (WOODWARD, 2000). A relação língua-cultura foi trazida à baila por estudos como os dos antropólogos Franz Boas, Edward Sapir e Claude Lévi-Strauss, no início do século XX (KRAMSCH, 1998; CUCHE, 1999).

Apesar de ter havido centenas de definiçôes somente no último século, às vezes conflitantes, parece haver concordância de que: a) culturas mudam; é mais importante aprender como aprender uma cultura do que aprender os "fatos" e "verdades" do momento; b) não há grupos ou sociedades sem cultura; c) lingua e cultura se relacionam e interagem intimamente (DAMEN, 1987, grifos meus, para ressaltar o enfoque deste estudo).

No campo do ensino de línguas estrangeiras (LEs), a consciência de que língua e cultura são inseparáveis somente começou a se fazer presente com os trabalhos de Dell H. Hymes (1972). Este autor, revisando os conceitos de competência e desempenho discutidos por Noam Chomsky, acrescentou-lhes aspectos socioculturais, contribuindo para que, a partir daí, o conceito de cultura passasse a receber mais atenção.

Numa sala de aula de inglês - língua estrangeira (ILE), os alunos constroem os significados sobre a cultura do outro a partir da sua própria (KRAMSCH, 1996) e, portanto, o aprendiz jamais chega ao real significado da cultura alheia, posto que a interpreta com o filtro de seus próprios olhos (aliás, mesmo a percepção sobre a sua própria cultura se dá através de interpretações). Kramsch (1996) sugere que o professor se valha dessa situação para um ensino mais eficiente: em vez de entender o ensino de cultura como transmissão de conhecimento, deve-se encorajar os alunos a utilizar esse conhecimento em favor de seus próprios objetivos e a encontrar relevância nos significados construídos. Para tal, o professor deve estimular uma discussão sobre cultura, procurando diferenças e similaridades com o próprio comportamento. É nesta situação que emerge o terceiro espaço (terceiro lugar, entrelugar, in-between, third places), onde o aprendiz se movimenta entre as 
culturas. Considerando que cultura é a força que orienta (MAHER, 2007a), os aprendizes funcionando no terceiro espaço estão sendo orientados pela própria cultura; ao mesmo tempo, a LE que estão falando, como parte intrínseca da cultura, os orienta para outra direção, advindo os conflitos.

No ensino de LE, é preciso desmistificar o conceito de uma cultura canônica e única. Existem diferenças significativas entre grupos de uma mesma nação, sendo impossível para um professor ensinar a cultura alheia, como se fosse uma só e completamente conhecida por um professor. Mais eficiente seria um debate em sala de aula em que todos os envolvidos (professores e alunos) compartilhem seus conhecimentos, contribuindo para uma discussão sobre diferenças culturais. É preciso também ter sempre em mente o perigo das generalizaçōes sobre a cultura do outro, que podem levar a "engessá-la", considerando-a imutável (MAHER, 1993; KRAMSCH, comunicação pessoal, 2011). Concordamos com Alfredo José da Veiga-Neto (2003), para quem

qualquer pedagogia multicultural não pode pretender dizer, aos que estão entrando no mundo, o que é o mundo; o que no máximo ela pode fazer é mostrar como o mundo é constituído nos jogos de poder/ saber por aqueles que falam nele e dele, e como se pode criar outras formas de estar nele. (VEIGA-NETO, 2003, p. 13).

Mesmo com olhos voltados para uma pedagogia multicultural, os conflitos culturais são inevitáveis - e, na verdade, positivos além de bastante proveitosos. Um dos fatores que contribuem para tais conflitos, que pretendemos explorar a seguir, é a questão da identidade do aprendiz, a qual, ao se fazer presente em seu discurso, é abalada no momento do encontro entre as culturas. Neste espaço discursivo em que há o conflito - não só cultural, mas também identitário - fica evidente o que Stuart Hall (2006) chama de crise de identidade: a perda de um "sentido de si" estável, chamada de deslocamento ou descentração do sujeito. É um duplo deslocamento/descentração dos indivíduos, tanto de seu lugar no mundo social e cultural quanto de si mesmos (HALL, 2006).

A crise acontece, portanto, quando algo que se supõe fixo é deslocado (WOODWARD, 2000); ela só se torna aparente no encontro com o outro, pois até então o indivíduo tem a ilusão de uma identidade unificada, completa, segura e coerente por ter construído uma cômoda história sobre ele mesmo ou uma confortadora "narrativa do eu" (HALL, 2006, p. 13). Porém, argumenta este autor, à medida que os sistemas de significação e representação cultural se multiplicam, multiplicam-se também as cambiantes possibilidades de identidades. Dessa forma, apesar de existir sempre algo imaginário ou 
fantasiado sobre a unidade da identidade, "ela permanece sempre incompleta, está sempre 'em processo', sempre 'sendo formada'” (HALL, 2006, p. 38). Faz parte desse processo uma falta de inteireza, a qual é preenchida a partir do exterior (HALL, 2006). Isso significa dizer que as identidades ficam aparentes a partir da diferença com o outro: somos aquilo que o outro não é (WOODWARD, 2000). E é esse confronto com o outro que nos interessa para este estudo.

Se a completude das identidades já é uma fantasia, a globalização contribui para que elas se tornem desvinculadas de tempos, lugares, histórias e tradições e pareçam "flutuar livremente" (HALL, 2006, p. 75), o que leva à produção de novas identidades. Nesse processo de ressignificação das identidades nacionais, há o convívio "com outras identidades que não se baseiam apenas nem necessariamente em sentimentos de pertença a um Estado, nação ou a um território particular" (BEREMBLUM, 2003, p. 89). É importante lembrar que, de forma alternativa, a globalização pode também levar a uma resistência que pode fortalecer e reafirmar algumas identidades nacionais e locais (WOODWARD, 2000; HALL, 2006). ${ }^{2}$

O efeito pluralizante da globalização sobre as identidades produz uma variedade de possibilidades e novas posições de identificação (WOODWARD, 2000; HALL, 2006). Assim, aqueles que se encontram na terra do outro negociam com as novas culturas, sem simplesmente serem assimilados por elas, nem perderem suas identidades. Esses indivíduos têm suas identidades como produto de várias histórias e culturas interconectadas, pertencendo, portanto, a culturas híbridas (GARCÍA CANCLINI, 2003). Embora o hibridismo na literatura se refira em geral a indivíduos dispersados de sua terra natal, os conceitos se aplicam perfeitamente à condição dos brasileiros nos EUA, dos quais alguns voltam ao Brasil e outros não. Isso porque mesmo os que voltam jamais terão apagadas as identidades produto de sua vivência no exterior, ou seja, jamais serão os mesmos que eram antes dessa experiência de contato com a cultura do outro. Num processo que Kathryn Woodward (2000) chamou de "circuito da cultura", a(s) cultura(s) molda(m) a identidade ao dar sentido à experiência e ao tornar possível optar, entre as várias identidades possíveis, por um modo específico de subjetividade.

\footnotetext{
${ }^{2}$ No Brasil, podemos citar, como exemplo de resistência e tentativa de fortalecimento da identidade nacional frente à globalização, o polêmico projeto de Lei n. 1676, do deputado do PCdoB Aldo Rebelo, que propóe proibir o uso de estrangeirismos em algumas situaçōes.
} 
Optar entre as várias identidades não significa que estas são fixas e inerentes ao sujeito, estando disponíveis como numa prateleira para serem conscientemente escolhidas. Concordamos com Alastair Pennycook (2008) que as identidades são performadas: esclarece-nos o autor que "performatividade [...] pode ser compreendida como o modo pelo qual desempenhamos atos de identidades como uma série contínua de performances sociais e culturais em vez de expressão de uma identidade anterior" (PENNYCOOK, 2008, p. 80).

Entendemos com isso que a identidade não é estática, nem uma essência do indivíduo. Assim, nos momentos de conflito cultural, os brasileiros estão performando identidades brasileiras que se materializam em seus discursos, ao mesmo tempo em que, falando inglês, também podem estar performando identidades outras, num processo que leva à hibridação. Dessa forma, a identidade não está fixa na língua, mas sim performada no discurso.

O que até aqui foi exposto sobre a questão da cultura e da identidade sugere que os conflitos culturais são inevitáveis e até positivos. Procurar apagálos em sala de aula, além de inócuo, não é de modo algum nosso objetivo. A proposta é buscar ampliar o conceito de cultura a ser discutido em sala de aula, procurando nos LDs oportunidades para tal. Ao incluir nas discussões um conceito mais amplo sobre o tema, torna-se possível utilizar-se do estranhamento do aluno frente à cultura do outro a fim de permitir o trânsito entre as culturas como uma experiência enriquecedora. Esse estranhamento seria, portanto, positivo e pode acontecer na própria sala de aula perante discussões - que ultrapassem, por exemplo, os limites da descrição do Halloween -, não dependendo somente da vivência no exterior (embora reconheçamos as diferenças entre experimentar o conflito cultural em sala de aula e fazê-lo no país falante da língua-alvo). Em suma, propomos uma pedagogia que explore a riqueza do espaço discursivo no qual os conflitos e estranhamentos acontecem.

\section{Procedimentos}

Para coletar histórias reais vividas por brasileiros no exterior que envolvessem conflitos culturais, foi necessária a elaboração de um questionário aberto (Anexo), o que permite aos respondentes se expressarem livremente, bem como decidirem o que dizer e como fazê-lo (NUNAN, 1992). Dessa forma, os participantes poderiam contar qualquer história que julgassem interessante sem que a pesquisadora interferisse no assunto a ser abordado. Assim, o respondente interpreta à sua maneira o que são "conflitos culturais", e a análise é feita a partir do que quer que seja que ele tenha contado. Itens 
fechados foram incluídos somente para coleta de informações sobre o perfil do participante. Os questionários foram, então, distribuídos por e-mail.

Obtivemos um retorno de sete questionários, dos quais escolhemos quatro para este artigo: aqueles cujos respondentes relacionaram seus conflitos culturais a algumas questôes linguísticas, como diferenças de pronúncia, entonação, gramática e vocabulário. Nesses quatro relatos, conforme veremos na análise, cultura está materializada no discurso e não somente no comportamento, evidenciando exemplos em que a forma linguística é veículo de significados, conforme já argumentamos. O que nos surpreendeu foi o fato de terem interpretado "conflitos culturais" como uma situação que envolvesse essas categorias linguísticas, por isso nossa escolha em analisar esses quatro questionários.

Os sujeitos escolhidos são fluentes na língua-alvo, pois o objetivo é entender quais dificuldades teriam pessoas com esse perfil. Evitamos, assim, a óbvia descrição de situaçôes em que a falta de conhecimento da língua teria sido um problema. Os respondentes são assim listados:

1. Uma médica psiquiatra (doutorado completo), 43 anos, moradora de Pullman (Washington, EUA), de 1996 a 2002. Terá referência F-WA-EUA (indicativo de sexo e lugar onde reside/residiu, isto é, estado e país);

2. Um professor universitário (doutorado completo), 37 anos, que morou em Long Island, EUA, de 2004 a 2008, durante o pós-doutorado. Será chamado M-LI-EUA;

3. Um diretor sênior de empresa (ensino superior completo), 45 anos, morador de Nova York há 23 anos. Será M-NY-EUA;

4. Um professor universitário (doutorado completo), 42 anos, que morou em Lancaster, Inglaterra, por um ano (2006-2007), para pesquisa científica. Será M-LAN-ING.

É importante ressaltar que não houve escolha intencional por uma amostra elitista de sujeitos. Isso é consequência do fato de que foi mais fácil encontrar brasileiros fluentes em inglês entre classes de maior prestígio, devido a questôes complexas de língua e poder que fogem ao nosso escopo. Além disso, já existem outros trabalhos que abarcam, com um enfoque bem diferente, sujeitos ocupando posição não elitista. ${ }^{3}$

${ }^{3}$ Veja, por exemplo, José Carlos Sebe Bom Meihy (2004) e Maxine L. Margolis (1994). 
Em seguida, comparamos as categorias linguísticas presentes nos relatos (pronúncia, entonação, gramática e vocabulário) às atividades em LDs que as abordam, com a finalidade de verificar se há um tratamento cultural dado às formas da língua. Foram selecionados quinze LDs datados de 1999 a 2006, bem como um mais antigo, de 1991: Flying Colours 2 (Intermediate) (1991); True Colors 2 (Low-Intermediate), 3 (Intermediate) e 4 (Upper-Intermediate) (1999); Adventures: Starter, Elementary e Pre-Intermediate (2002); American Inside Out A e B (Upper-Intermediate) (2003); New Headway (UpperIntermediate) (2003); American Headway $3 A$ e $3 B$ (Intermediate) (2003); Summit 2 (Advanced) (2006); Top Notch 2 (Pre-Intermediate) e 3 (Intermediate) (2006).

A escolha dos LDs se deu a partir da sugestão de alguns professores de escolas de idiomas, que os utilizavam e os elogiaram. No caso dos dois livros mais antigos, a professora que os recomendou comentou utilizar apenas algumas atividades selecionadas, como exercício extra; porém, decidimos por incluí-los no estudo assim mesmo, para aumentar as possibilidades na análise dos dados. Os níveis foram escolhidos por conterem as categorias linguísticas apreendidas dos relatos dos questionários.

Além de observarmos o trato dado a algumas formas linguísticas nos LDs, também procuramos referências explícitas a questóes culturais, tendo as encontrado em textos sobre questôes comportamentais, sobre informaçóes históricas e folclórico-turísticas, sobre personalidades de destaque e sobre curiosidades diversas. Isso sugere que o modo como os LDs são estruturados parece separar o que é linguístico (exercícios de gramática, pronúncia etc.) do que é cultural (textos informativos).

As histórias coletadas pelos questionários foram divididas de acordo com seus temas, quais sejam: 1) diferenças de pronúncia e entonação entre a língua materna (LM) e a LE que geram desentendimentos; 2) aspectos culturais intrínsecos à gramática da LE; (3) palavras que aparentemente teriam o mesmo uso em LM e LE, bastando apenas traduzir. Cada relato será analisado separadamente, sendo contrastado com conteúdos dos LDs, e, em seguida, será feita uma análise geral envolvendo conceitos que perpassam todos os relatos.

\section{Resultados e discussão}

Sete questionários foram obtidos, três dos quais fazem menção aos seguintes assuntos: diferentes protocolos sociais quando se está almoçando com colegas; a questão da pontualidade às festas; e diferenças no procedimento de instalação de telefone, que geraram mal-entendidos (esses relatos foram analisados em trabalho 
não publicado). Para este estudo, selecionamos os outros quatro, que relacionaram diferenças culturais explicitamente ao uso da língua. Estes participantes relataram situaçôes em que o uso equivocado de certos recursos linguísticos gerou desconforto e/ou a impressão de falta de polidez por parte dos brasileiros. Por isso, o componente cultural mais presente na análise acaba sendo a polidez intercultural.

Esse recorte nos questionários é feito com a finalidade de explorar especificamente a relação língua-cultura e o conceito segundo o qual forma éveículo de significado.

\section{Análise de cada relato}

\section{Pronúncia e entonação}

Um relato que envolve a pronúncia do nome é uma boa história para iniciar a análise, já que todos os LDs, desde seus níveis introdutórios, encerram conversas em que os interlocutores se apresentam. Talvez não seja tão óbvia a importância da pronúncia do nome, ficando então a cargo do aprendiz pronunciar da maneira que lhe apetece. Adequar-se a pronunciar o próprio nome do modo como falantes de inglês o fariam pode parecer aquiescência ao imperialismo americano. ${ }^{4}$ Porém, a opção pela pronúncia em sua LM pode levar a mal-entendidos curiosos, como foi o caso da médica psiquiatra F-WA-EUA:

Logo nos primeiros dias, ao apresentar-me aos colegas, dizendo de onde vinha, o que fazia, etc, mencionava que era casada com DANIEL. A pronuncia americana de DANIEL é "Dêniel", porém, apesar de estar nos EUA, eu continuei a chamar meu marido de "Daniél", como se pronuncia no Brasil. Só que "Daniél" em inglês significa DANIELLE, ou seja, pessoa do sexo feminino. Isso foi razão para uma pequena confusão: por um curto espaço de tempo, até que as pessoas conhecessem meu marido Daniel, alguns colegas pensaram que eu era gay, casada com uma moça chamada Danielle. ${ }^{5}$

\footnotetext{
${ }^{4}$ Veja Pennycook (1994) e Robert Phillipson (1996) para uma discussão sobre o imperialismo americano e inglês, por meio da disseminação da língua inglesa no mundo. Veja também A. Suresh Canagarajah (1999), que, assim como Pennycook (1994), discorre sobre a pedagogia crítica, uma pedagogia de resistência ao imperialismo. Veja Plinio Apuleyo Mendoza et al. (1996) para uma explicação sobre o surgimento dos antiimperialistas nos países hispanos da América Latina.

${ }^{5}$ As transcrições são fiéis e, portanto, foram mantidos quaisquer equívocos que possam ter surgido.
} 
A fluência em inglês não impediu que F-WA-EUA passasse equivocadamente informaçôes básicas sobre si. A importância da pronúncia do nome deve ser, portanto, levantada em sala de aula, conscientizando os aprendizes sobre o assunto. Uma vez ciente, será mais fácil o aprendiz transitar no terceiro espaço e usar o conhecimento adquirido em benefício próprio. A escolha sobre como pronunciar seu próprio nome será do aprendiz depois de ter consciência das implicações. Obviamente, não será uma escolha neutra, pois questões de identidade se fazem presentes nesse espaço discursivo de trânsito entre as culturas. O que propomos é não ignorar um conflito cultural-identitário como esse que possa surgir em sala de aula. Por exemplo, caberiam numa situação como essa até mesmo discussões sobre o imperialismo americano/inglês (PENNYCOOK, 1994; PHILLIPSON, 1996) e pedagogia de resistência (CANAGARAJAH, 1999), mesmo em níveis introdutórios de ensino de ILE.

Outra questão que não deve ser ignorada são os exercícios de entonação. Todos os LDs analisados, em seus diversos níveis, apresentam exercícios nos quais os aprendizes devem praticar entonação ascendente ou descendente (rising and falling intonation) de acordo com o tipo de pergunta: wh questions, yes/ no questions, tag questions etc. No Brasil, é perfeitamente aceitável entonação descendente para perguntas que requerem respostas do tipo sim/não, o que não se aplica em inglês, conforme constatou o pós-doutorando M-LI-EUA:

Estávamos eu e o pessoal do meu laboratório almoçando juntos e conversando sobre nosso trabalho. Quando planejávamos os próximos passos da pesquisa, perguntei à PI (principal investigator, ou seja, chefe de laboratório) se ela faria um determinado experimento. Ela teve uma reação inesperada, estranhando minha pergunta. Então, perguntou se eu estava mandando que ela fizesse o experimento. Eu disse que não, estava somente perguntando. Ela respondeu "ah, é que você falou com autoridade". Mais tarde, conversando com uma pessoa, que é professora de inglês e que também estava à mesa, entendi que, além de ter errado a ordem do sujeito e verbo na pergunta, errei na entonação. Foi isso que gerou o "tom" mandão do que era para ser uma pergunta: you're gonna do that? (falling intonation) quando deveria ter dito are you gonna do that? (rising intonation). [Grifos do original.]

Se a entonação tivesse sido apropriadamente empregada, o erro gramatical não teria sido um ruído na comunicação neste caso. Esse relato provoca aqueles que ignoram os exercícios de repetição destinados à prática da pronúncia e entonação de perguntas. 
Por razōes históricas, há um certo preconceito em relação aos exercícios de entonação por estarem associados aos exercícios comportamentalistas de repetição. Estes exercícios receberam o aval da ciência - importante em todo o período pósiluminista - com os trabalhos de Burrhus F. Skinner, em especial O comportamento verbal (1957). Discorrendo sobre o comportamento ecoico (de eco, ou repetição), Skinner afirma que todo aprendizado se dá pelo condicionamento. Embora Skinner não tenha se ocupado do ensino de LE, esse livro acabou tendo influência nos métodos de ensino de línguas e no campo da linguística de um modo geral. A partir da década de 1970, as teorias comportamentalistas são duramente criticadas (CHOMSKY, 1959; WIDDOWSON, 1991) e perdem seu espaço para darem lugar a teorias que moldariam o comunicativismo. Acontece que o componente cultural, já reconhecidamente indispensável em abordagens comunicativas, teve uma presença extremamente tênue, quase imperceptível, em abordagens resultantes do mecanicismo estruturalista comportamental (PEDROSO, 1999). Isso implica dizer que, supostamente, exercícios de repetição são às vezes mal vistos por se apresentarem como comportamentalistas e aculturais. De fato, esclarece Brian Morgan (1997) que, com o movimento comunicativo, nocional-funcional e abordagens baseadas em tarefas, caiu o interesse pelo ensino de pronúncia.

No relato acima, o conflito acontece no momento em que se faz presente no discurso de M-LI-EUA a identidade de seu "eu" da LM. Morgan (1997), estudando a relação entre identidade e entonação, enfatiza a importância de uma pedagogia que engloba o ensino de entonação e leva em consideração também contextos sociais, pois procura dar conta de perguntas como "o que a entonação significa aqui?", "Quem está falando?", "Por que estão tendo essa conversa?”, “O que querem com a linguagem?”. Novamente, o transitar entre as culturas é um espaço rico a ser explorado até mesmo em inocentes exercícios de pronúncia.

\section{Gramática}

O fragmento gramatical mencionado por um respondente é o uso de would, could e can, verbos que são, portanto, o foco desta seção. As diferenças entre would e o uso de futuro do pretérito em português, assim como could e também can, foram notadas pelo diretor sênior de empresa, M-NY-EUA:

No começo tinha problemas em botar o "would you", or "could you" or o "can you", na frente dos pedidos. Portanto falar para alguém ligar a luz, eh mais do que "Turn on the lights" apesar de estar gramaticalmente correto. Em português, o "could you" pode ser posto na informaçẫo da pergunta, em vez de acrescentar palavras. As pessoas se ofendiam. 
Ao procurar referências a esses modais nos LDs, observamos que would, could, entre outros, são apresentados em vários momentos. É comum em níveis introdutórios a ênfase cair no uso gramaticalmente correto, deixando para níveis mais adiantados os aspectos culturais atrelados a eles, como o efeito de polidez ao se pedirem favores. É o que acontece com as séries analisadas True Colors, Summit e New Headway: somente nos níveis intermediários esses verbos aparecem para expressar polidez ao pedir um favor. Em True Colors 3 ainda há o agravante de estar o would embutido na expressão would you mind (MAURER; SCHOENBERG, 1999b, p. 6-7) como se não pudesse ser utilizado isoladamente com o mesmo efeito de polidez.

Este é um aspecto cultural facilmente ignorado nos cursos de inglês, já que o foco do LD acaba caindo, primeiramente, no uso gramaticalmente correto, ou seja, na prática da inversão da ordem sujeito-verbo. E, mesmo que o aprendiz entenda que would é equivalente a futuro do pretérito em português, could significa 'poderia' e can equivale a 'pode', o professor deveria ainda trazer à consciência as diferenças de uso dessas palavras em LM e LE. Por exemplo, em português, a polidez pode se expressar na entonação, dispensando o uso de poderia, o que não é comum em inglês.

Se no começo a(s) identidade(s) brasileira(s) de M-NY-EUA se fazia(m) presente(s) em seu discurso, sua compreensão sobre o fenômeno linguístico em questão o levou a se utilizar da forma mais adequada em inglês. Esse é o produto desejável - a competência simbólica - de uma pedagogia que explore o espaço de conflito com vistas ao empoderamento, conforme vimos argumentando.

Este relato nos faz repensar o conceito de equivalência entre LM e LE. Estudos da tradução, ao problematizarem a questão da fidelidade, propõem um redirecionamento da noção de equivalência, argumentando que duas "roupagens" linguísticas não resultam numa mesma mensagem, mas sim em duas mensagens (AUBERT, 1994, p. 31-32; grifos do original). O que há, segundo este autor, é uma aproximação suficiente entre as duas línguas para que uma seja percebida como tradução - ou equivalente - da outra. Assim, percebemos que would, por exemplo, é "equivalente" ao futuro do pretérito em português, porém, cada qual com sua carga de significados instáveis, o que pode causar o equívoco relatado pelo sujeito da pesquisa.

Essas são questões que devem surgir em sala de aula quando do ensino de estruturas linguísticas, evidenciando a importância da integração entre forma e significado. Atividades com os modais não deveriam ser reduzidas a meros exercícios gramaticais, de colocação das palavras no lugar certo, ou estruturais, do tipo would you mind + complemento a ser substituido pelo aluno. 


\section{Vocabulário}

Similarmente ao caso acima, existem outras palavras em LE que, embora tenham sua tradução amplamente reconhecida, são utilizadas em situaçōes um pouco diferentes, desafiando novamente o conceito de equivalência. Um caso desse tipo foi vivenciado pelo professor universitário M-LAN-ING:

Nos meus primeiros dias na Inglaterra, experimentei uma certa dificuldade em me fazer entender pelos motoristas do ônibus que eu utilizava para ir à universidade todos os dias. No começo, imaginei que era porque eu usava frases muito longas e os estudantes simplesmente falavam algo do tipo "Return ticket to uni, please". Era algo de fato intrigante, pois, por pior que fosse minha capacidade de falar inglês, o motorista poderia deduzir facilmente o que eu estava pedindo, já que era o que todo mundo que subia no ônibus pedia, ou seja, um bilhete de ida e volta para a universidade. Só depois me dei conta de que na Inglaterra é comum uma certa polidez oficial, manifestada, por exemplo, no uso obrigatório do "please" no final de todas as frases onde algo é solicitado. Um fato curioso associado a isso é que uma das maneiras dos ingleses manifestarem o seu descontentamento com a atitude, comum entre os brasileiros, de não usar o "please" é fazer de conta que não entendem.

De fato, há nos LDs oportunidade para se trazer à consciência essa diferença cultural nas situações em que o please é obrigatório e o por favor nem tanto. Retomando o New Headway, na unidade 4, a qual apresenta os modais would, could, can, would you mind, há uma atividade cujo subtítulo é "Everyday English: Requests and Offers", em que o aluno deve ligar as perguntas do quadro A com as respectivas respostas do quadro B. No quadro A, lê-se:

1. Could you bring us the bill, please?

2. Would you give me your work number, please?

3. Can I help you?

4. Two large coffees, please.

5. Can you tell me the code for Paris, please?

6. I'll give you a lift if you like.

7. Would you mind opening the window?

8. Could I have extension 238, please?

(SOARS; SOARS, 2003c, p. 37). 
Percebe-se o uso corriqueiro de please em situações em que, no Brasil, às vezes o falante dispensa sem ser considerado rude por isso, como por exemplo, pedir o telefone do trabalho de alguém ou pedir café numa lanchonete. Em português, o uso do vocábulo gostaria, nas situaçóes 2,4 e 5, por exemplo, denota a polidez necessária a ponto de talvez dispensar o uso de por favor, o que não é verdadeiro em inglês. Além disso, como já foi comentado anteriormente, a entonação em português muitas vezes denota a polidez necessária para determinadas situaçōes, dispensando palavras que surtam tal efeito.

Já em Adventures: Elementary, a atividade cuja intenção é praticar pedidos de favores induz o aluno a não utilizar o please. $\mathrm{O}$ texto que apresenta as expressões para pedido de favores é um diálogo dividido em cinco partes, que inclui um pai e três adolescentes: filha, filho e vizinho. $O$ pai pede ao filho que lave os pratos, mas ele argumenta que é a vez da irmã; porém, ela está ocupada ensinando matemática ao vizinho, que havia lhe pedido ajuda com essa matéria (WERTZ, 2002a, p. 22). Em seguida a esse diálogo, há um exercício de compreensão de texto e, depois, uma atividade para praticar o tema central do texto, isto é, pedir favores ("Dialogue: Making Requests"). O excerto retirado dos diálogos para servir de modelo é o único em que o please não aparece:

A: Nikki, can you help me with my Maths homework?

B: Why? What's the problem?

A: I don't understand it.

B: Oh, right. Yes, OK. I suppose so.

A: Great, thanks.

(WERTZ, 2002a, p. 23).

Embora please tenha aparecido em outras instâncias dos diálogos, aquele que servirá de modelo para os alunos (como um template) não traz essa palavra, o que induz o aprendiz a não utilizá-la. Se o fato passar despercebido, a questão da polidez nos pedidos de favores não será trazida à baila. Pelos dois últimos relatos, compreendemos que utilizar-se dos mesmos recursos da LM para expressar polidez na LE não surte o mesmo efeito.

Por serem sutis, essas diferenças culturais materializadas na linguagem não são facilmente percebidas pelos aprendizes. É preciso, portanto, que essas questôes sejam discutidas, trazidas à consciência, e que o conceito de equivalência seja questionado. 


\section{Análise geral: considerações adicionais}

Mesmo que a concepção sobre a inseparabilidade entre língua e cultura seja comumente aceita no âmbito dos estudos sobre ensino/aprendizagem de línguas, há quem defenda uma pedagogia que não abarque a dimensão cultural, como é o caso de Christopher J. Hall (2001). Para ele, os aspectos culturais devem ser minimizados a fim de favorecer o estudo das estruturas linguísticas. $\mathrm{O}$ autor se pergunta qual a validade de utilizar, como panorama cultural, o almoço de uma família branca norte-americana ou um casal num pub inglês, se a maioria dos aprendizes não vive essas realidades. $\mathrm{O}$ argumento norteador de uma pedagogia dissociada da questão cultural é evitar a imposição da cultura da língua-alvo sobre os países não falantes dessa língua.

Não nos interessa entrar no mérito da questão sobre a imposição cultural; basta esclarecer que estamos de acordo com estudos que sugerem a pedagogia crítica como resposta a tal imposição: resumidamente, autores como Pennycook (1994), Canagarajah (1999), Cox e Assis-Peterson (1999) rejeitam a ideia de que o ensino de ILE é neutro e livre de ideologias. Sugerem então que, se o aprendizado de uma língua é ideológico, a solução não é fugir de seu caráter político, mas negociar com as agências de poder para o empoderamento pessoal e coletivo. Isso significa que, em vez de somente repetir a língua em estudo e aceitar os valores que ela encerra, os alunos devem se tornar agentes da língua, usando-a de acordo com suas aspirações, necessidades e valores (CANAGARAJAH, 1999). Além dos argumentos a favor da pedagogia crítica, teorias sobre identidade também conseguem dar conta da questão da imposição cultural. Bonny Norton (1997), por exemplo, demonstra que não se abre mão de uma cultura ou identidade para assimilar outra; adapta-se à cultura local, resultando em "identidades biculturais" (NORTON, 1997, p. 426) ou, diríamos, híbridas. Rejeitamos, portanto, a possibilidade de uma pedagogia que conseguisse separar língua e cultura.

Mesmo que a separação fosse desejável, não seria possível. Patricia A. Duff e Yuko Uchida (1997) exemplificam essa impossibilidade ao analisar a prática pedagógica de quatro professores de ILE no Japão (dois americanos e dois japoneses): nenhum deles percebe seu papel de professores como necessariamente envolvendo o ensino explícito de cultura; contudo, em suas práticas e materiais utilizados, o ensino implícito de cultura fica evidente, sugerindo que a cultura é componente sempre presente no ensino, mesmo que não haja uma consciência sobre o fato. Acrescenta Terezinha de Jesus Machado Maher (2007b, p. 89) que na sala de aula não ocorre a simples justaposição de 
culturas; ao contrário, "as identidades culturais nela presentes (tanto de professores, quanto de alunos) esbarram, tropeçam umas nas outras o tempo todo, modificando-se e influenciando-se continuamente", o que a caracteriza como um espaço de interculturalidades.

Nossos resultados são uma exemplificação concreta do termo línguacultura, utilizado na literatura (por exemplo, KRAMSCH, 1998) para sugerir sua inseparabilidade. Há nos quatro relatos um significado que não pode ser ignorado. Ao atenderem à solicitação de relatar uma situação em que diferenças culturais se tornaram um ruído na comunicação, os sujeitos deste estudo demonstraram uma concepção de cultura que está além daquela concepção ligada a informações sobre lugares, pessoas, fatos históricos, comumente encontrada nos textos dos LDs. Percebemos que esses sujeitos claramente concebem a língua como veículo de cultura. Este fato é importante porque ilustra aquilo que Paulo Freire (1975) teorizou ao afirmar que os alunos não são cabeças vazias onde se deposita conhecimento.

Enquanto estudos clamam por um ensino de LEs que fuja do esquema de tratar a cultura como conjunto de conteúdos informativos e exóticos sobre uma determinada comunidade e a língua como estrutura independente da rede social que a envolve (SANTOS, 2004; veja também PEDROSO, 1999; RIERA, 2005), devemos admitir que existem aprendizes que já reconhecem esses conceitos.

Se assim o é, então por que, apesar de terem certo conhecimento da língua inglesa, só se deram conta das diferenças culturais ao se depararem com as situações que descreveram? Conforme já mencionamos, os conflitos culturais e crises de identidades provocam mudanças no sujeito; ele nunca será o mesmo depois desses fenômenos. Acreditamos que o conceito de língua que o sujeito traz antes dos conflitos seja provavelmente estruturalista, legado do iluminismo. Conceitos estruturalistas influenciam o modo como os aprendizes de línguas procuram os referentes exatos entre a LM e a L2, sendo de difícil percepção que please e por favor, por exemplo, não são um "decalque" um do outro. Somente os conflitos trouxeram essa consciência.

Isso posto, para responder a pergunta do parágrafo acima, apostamos no terceiro espaço, onde os conflitos acontecem, como um elemento essencial na prática pedagógica: é no momento do conflito que essas questôes se fazem mais aparentes e podem promover as mudanças nos sujeitos no que concerne ao conceito de língua. Trazer essas questôes à consciência é importante para auxiliar o aluno a movimentar-se entre as culturas e contribuir para o desenvolvimento da competência simbólica. 
É nesse terceiro espaço que observamos aquilo que Cox e Assis-Peterson (2007) chamaram "vazamento" e "fluidez" das línguas (ou, ainda, "permeabilidade" para MAHER, 2007b), caracterizado pelo momento em que o brasileiro se apropria da língua inglesa e produz novos sentidos. É uma janela onde as duas línguas se fundem num processo fluido para, depois do desconforto, tentar retomar seu curso "normal".

Essa tentativa de retomar seu curso normal seria o desejo do brasileiro de se identificar com o outro; obviamente, ele pode querer, ao contrário, marcar sua identidade, calcando-se na diferença. Ele vai construindo suas identidades plurais por meio de sua experiência vivida no "terceiro espaço". A consciência cultural permite que o sujeito opte por um modo específico de subjetividade, opte entre marcar propositalmente sua identidade ou tentar identificar-se com o outro. $E^{\prime}$ importante ressaltar que os sujeitos participantes desta pesquisa não estão reivindicando sua identidade através das diferenças (WOODWARD, 2000), mas sim buscando incorporar fragmentos da cultura americana/inglesa (nestes casos, para evitarem serem considerados rudes), fato que contribuirá para a construção de sua identidade. Essa identificação com o outro acontece porque estamos tratando de um bilinguismo de prestígio em contraposição ao bilinguismo de minorias, que procura anular (ou silenciar) o outro (MAHER, 2007b).

É importante ressaltar que identificar-se ou não com o outro não é uma relação maniqueísta. Em outras palavras, o sujeito bilíngue, que funciona no terceiro espaço e está em permanente construção, é um sujeito híbrido (MAHER, 2007b). Isso implica dizer, num paralelo com o sujeito índio de Maher (2007b), que os participantes deste estudo não são escravos de sua cultura nem tampouco clones da cultura do outro.

Em suma, se o transitar entre as línguas e culturas promove mudança no indivíduo e maior consciência linguístico-cultural, sugerimos que os conflitos (estranhamentos) que surgem na sala de aula não sejam ignorados nem tratados como erros, mas sim explorados de modo a promover a competência simbólica. Isso é parte do processo de aprender uma LE.

\section{Considerações finais}

Conforme argumentamos, o componente cultural está inevitavelmente presente nas aulas, seja de maneira mascarada ou mais explícita. O problema não é a ausência - impossível - da cultura, mas sim o conceito de cultura aparentemente veiculado pelos LDs, ou seja, um conceito segundo o qual língua e cultura são por vezes entidades distintas: os LDs apresentam, por um 
lado, como fatos culturais textos sobre filmes, música, personalidades e história relacionados a outros países e, por outro lado, atividades gramaticais ignorando-se os aspectos culturais que lhe são intrínsecos. Esse tipo de abordagem cultural é a que menos promove compreensão de situações linguístico-culturais futuras, quando da interação com falantes da língua-alvo. A abordagem à qual recorremos é aquela que procura entender como a língua, concebida como discurso, veicula cultura. Assim, é importante compreender não só como se comportar em outros países, mas também por que a pronúncia do próprio nome pode ser tão importante, por que o brasileiro pode ser considerado rude mesmo que acredite estar sendo educado, por que diferentes entonações geram sentidos distintos, às vezes não aquele pretendido etc.

O que propomos é que o professor amplie a concepção de cultura veiculada pelas atividades linguísticas (pronúncia, gramática, vocabulário etc.) dos LDs, procurando nas liçóes as oportunidades para trazer consciência cultural à sala de aula e indo além da inocuidade dos textos informativos.

Nossos dados lançam luz sobre algumas questôes. Em primeiro lugar, constituem exemplos concretos da inseparabilidade entre língua e cultura, conceito bastante repetido, mas talvez pouco compreendido na prática. Os dados respondem perguntas sobre como abordar a cultura em sala de aula de modo a promover um conhecimento do qual o aprendiz realmente possa se valer nas interações com falantes da língua-alvo. Em segundo lugar, demonstram como os aprendizes são subestimados em relação à noção de língua e cultura que já carregam consigo. A riqueza de seus conhecimentos prévios nunca pode ser desprezada, conforme já nos alertava Paulo Freire. Terceiro, as histórias demonstram de que maneira a fluência não é fator determinante para livrar o aprendiz dos equívocos.

O conceito de cultura veiculado pela língua tal qual é concebido neste estudo é o fator que, acreditamos, contribuirá para que o aprendiz passe a movimentar-se entre as culturas, utilizando o conhecimento em benefício próprio. Esse é um fator que ajuda a compreender melhor os conflitos e facilitar a comunicação, lembrando que a completa inexistência deles é utópica e até indesejável, pois significaria ausência de riqueza cultural. 


\section{Referências}

AUBERT, F. H. As (in)fidelidades da tradução: servidões e autonomia do tradutor. 2. ed. Campinas: Unicamp, 1994.

BEREMBLUM, A. A invenção da palavra oficial: identidade, língua nacional e escola em tempos de globalização. Belo Horizonte: Autêntica, 2003.

CANAGARAJAH, A. S. Resisting Linguistic Imperialism in English Teaching. Oxford (UK): Oxford University Press, 1999.

CHOMSKY, N. A Review of B. F. Skinner's Verbal Behavior. Language, v. 35, n. 1, p. 26-58, 1959.

COX, M. I. P.; ASSIS-PETERSON, A. A. de. Critical Pedagogy in ELT: Images of Brazilian Teachers of English. TESOL Quarterly, v. 33, n. 3, p. 433-452, Autumn 1999.

. Transculturalidade e transglossia: para compreender o fenômeno das fricçōes lingüístico-culturais em sociedades contemporâneas sem nostalgia. In: CAVALCANTI, M. C.; BORTONI-RICARDO, S. M. (Ed.). Transculturalidade, linguagem e educação. Campinas: Mercado das Letras, 2007. p. 45-66.

CUCHE, D. A noção de cultura nas ciências sociais. Bauru: Edusc, 1999.

DAMEN, L. Culture Learning: The Fifth Dimension in the Language Classroom. Reading; Menlo Park; Don Mills: Addison-Wesley, 1987.

DUFF, P. A.; UCHIDA, Y. The Negotiation of Teachers' Sociocultural Identities and Practices in Postsecondary EFL Classrooms. TESOL Quarterly, v. 31, n. 3, p. 451-486, Autumn 1997.

FREIRE, P. Educação política e conscientização. Lisboa: Sá a Costa, 1975. (Cadernos Livres, 6).

GARCÍA CANCLINI, N. Culturas híbridas: estratégias para entrar e sair da modernidade. 4. ed. São Paulo: Edusp, 2003.

HALL, C. J. Lenguaje, mente y cultura: reflexiones sobre las fronteras lingüísticas y la enseñanza de idiomas en el umbral del siglo XXI. Estudios de Lingüistica Aplicada, v. 19, n. 33, p. 13-30, 2001.

HALL, S. A identidade cultural na pós-modernidade. DP\&A: Rio de Janeiro, 2006.

HYMES, D. On Communicative Competence. In: PRIDE, J. B.; HOLMES, J. (Ed.). Sociolinguistics. Harmondsworth: Penguin, 1972.

KRAMSCH, C. Context and Culture in Language Teaching. 3. ed. Oxford (UK): Oxford University Press, 1996. . Language and Culture. Oxford (UK): Oxford University Press, 1998. . From Communicative Competence to Symbolic Competence. The Modern Language Journal, v. 90, p. 249-252, 2006. 
KRAMSCH, C. The Language/Culture Nexus in Language Study. In: CONGRESSO BRASILEIRO DE LINGUÍSTICA APLICADA, 9., 2011. Caderno de Resumos... Rio de Janeiro: ALAB, 2011. Trabalho discutido em mesa-redonda.

MAHER, T. M. Culture in the Foreign Language: Going beyond Halloween and Apple Pie. APLIESP Newsletter, out. 1993.

. A educação do entorno para a interculturalidade e o plirilingüismo. In: KLEIMAN, A. B.; CAVALCANTI, M. C. (Ed.). Linguistica Aplicada: suas faces e interfaces. Campinas: Mercado de Letras, 2007a. p. 255-270.

. Do casulo ao movimento: a suspensão das certezas na educação bilíngue e intercultural. In: CAVALCANTI, M. C.; BORTONI-RICARDO, S. M. (Ed.). Transculturalidade, linguagem e educação. Campinas: Mercado das Letras, 2007b. p. 67-94.

MARGOLIS, M. L. Little Brazil: An Ethnography of Brazilian Immigrants in New York City. New Jersey: Princeton, 1994.

MEIHY, J. C. S. B. Brasil fora de si. Experiências de brasileiros em Nova York. São Paulo: Parábola, 2004.

MENDOZA, P. A.; MONTANER, C. A.; LLOSA, A. V. Manual del perfecto idiota latinoamericano. Barcelona: Plaza Janés, 1996.

MORGAN, B. Identity and Intonation: Linking Dynamic Processes in an ESL Classroom. TESOL Quarterly, v. 31, n. 3, p. 431-450, 1997.

NORTON, B. Language, Identity, and the Ownership of English. TESOL Quarterly, v. 31, n. 3, p. 409-429, 1997.

NUNAN, D. Research Methods in Language Learning. Cambridge (UK): Cambridge University Press, 1992.

PEDROSO, S. F. A carga cultural compartilhada: a passagem para a interculturalidade no ensino de português língua estrangeira. 1999. 140 f. Dissertação (Mestrado em Linguística Aplicada) - Instituto de Estudos da Linguagem, Universidade Estadual de Campinas, Campinas, 1999.

PENNYCOOK, A. The Cultural Politics of English as an International Language. London; New York: Longman, 1994.

. Uma lingüística aplicada transgressiva. In: MOITA LOPES, L. C. (Ed.). Por uma lingüistica aplicada indisciplinar. 2. ed. Parábola: São Paulo, 2008. p. 67-84. PHILLIPSON, R. Linguistic Imperialism. 3. ed. Oxford (UK): Oxford University Press, 1996.

RIERA, M. J. C. Currículo interculturalista e ensino de espanhol no Brasil: lendas folclóricas, memórias e escrita. 2005. 109 f. Dissertação (Mestrado em Linguística Aplicada) - Instituto de Estudos da Linguagem, Universidade Estadual de Campinas, Campinas, 2005. 
SANTOS, E. M. O. Abordagem comunicativa intercultural (ACIN): uma proposta para ensinar e aprender língua no diálogo de culturas. 2004. 432 f. Tese (Doutorado em Linguística Aplicada) - Instituto de Estudos da Linguagem, Universidade Estadual de Campinas, Campinas, 2004.

SKINNER, B. F. O comportamento verbal. São Paulo: Cultrix, 1957.

VEIGA-NETO, A. Cultura, culturas e educação. Revista Brasileira de Educação, Rio de Janeiro, v. 23, p. 5-15, ago. 2003.

WIDDOWSON, H. G. O ensino de línguas para a comunicação. Campinas: Pontes, 1991.

WOODWARD, K. Identidade e diferença: uma introdução teórica e conceitual. In: SILVA, T. T. da. (Ed.). Identidade e diferença: a perspectiva dos estudos culturais. Petrópolis: Vozes, 2000. p. 7-72.

\section{Livros didáticos analisados}

GARTON-SPRENGER, J.; GREENALL, S. Flying Colours 2. Oxford (UK): Heinemann, 1991.

KAY, S.; JONES, V. American Inside Out: Book A. Oxford (UK): Macmillan, 2003a.

American Inside Out: Book B. Oxford (UK): Macmillan, 2003b.

MAURER, J.; SCHOENBERG, I. E. True Colors 2. White Plains: Longman, 1999a. . True Colors 3. White Plains: Longman, 1999b. . True Colors 4. White Plains: Longman, 1999c.

SASLOW, J.; ASCHER, A. Summit 2. White Plains: Pearson Longman, 2006a. . Top Notch 2. White Plains: Pearson Longman, 2006b.

. Top Notch 3. White Plains: Pearson Longman, 2006c.

SOARS, L.; SOARS, J. American Headway 3A. Oxford (UK): Oxford University Press, 2003a.

. American Headway 3B. Oxford (UK): Oxford University Press, 2003b. . New Headway. 2. ed. Oxford (UK): Oxford University Press, 2003c.

WERTZ, B. Adventures: Elementary. Oxford (UK): Oxford University Press, 2002a.

. Adventures: Starter. Oxford (UK): Oxford University Press, 2002b. . Adventures: Pre-Intermediate. Oxford (UK): Oxford University Press, 2002c. 


\section{ANEXO: Questionário aplicado}

Nome:

Idade:

Profissão no Brasil:

Profissão no país estrangeiro onde reside/residiu:

Local de residência no exterior (país, estado, cidade):

Escolaridade

( ) Ensino Fundamental incompleto / ( ) Ensino Fundamental completo

( ) Ensino Médio incompleto / ( ) Ensino Médio completo

( ) Ensino Superior incompleto / ( ) Ensino Superior completo

( ) Pós-graduação:

1) Há quanto tempo reside/residiu no exterior (coloque os anos de entrada e, se for o caso, de saída)?

2) Como você classifica seu nível de inglês?

Fala: ( ) bem; ( ) razoavelmente; ( ) pouco; ( ) nada

Escreve: ( ) bem; ( ) razoavelmente; ( ) pouco; ( ) nada

Compreende: ( ) bem; ( ) razoavelmente; ( ) pouco; ( ) nada

Lê: ( ) bem; ( ) razoavelmente; ( ) pouco; ( ) nada

3) Conte uma situação pela qual tenha passado, que envolva problemas decorrentes de diferenças culturais. Tais problemas podem ser mal-entendidos, desconforto, embaraço. Pode ser até uma situação engraçada. Conte quantas histórias desejar, ocorridas no trabalho, no diaa-dia, numa festa, fazendo compras, indo ao médico etc.

Exemplo:

Situação: Na cozinha de uma casa americana, aconteceu o seguinte diálogo entre uma donade-casa americana e uma estudante brasileira:

Americana: Acabei de fazer um bolo. Quer um pedaço?

Brasileira: (sorrindo) Não, obrigada.

Americana: Tem certeza?

Brasileira: Tenho. Obrigada.

Americana: (colocando o bolo de volta no balcão da cozinha) $O K \ldots$... 
O problema: A brasileira na verdade queria o bolo; porém, como no Brasil é comum rejeitar mais algumas vezes, a brasileira esperava que a americana insistisse mais um pouco até finalmente dizer que queria um pedaço. A brasileira sentiu que se aceitasse de primeira, pareceria mal-educada. Agindo de acordo com a cultura brasileira, ficou sem o pedaço de bolo que queria). ${ }^{6}$

4) Estaria disponível para uma entrevista complementar ao questionário, se necessário (via MSN ou e-mail)? Se sim, deixe aqui seu MSN e e-mail:

\footnotetext{
${ }^{6}$ A história está em terceira pessoa porque foi tirada de um artigo da Profa. Dra. Tereza Machado Maher (Unicamp), publicado na APLIESP Newsletter, de outubro de 1993, sob o título "Culture in the Foreign Language: Going Beyond Halloween and Apple Pie". Já a sua história obviamente pode ser em primeira pessoa (exemplo: EU estava num metrô, quando...).
}

Recebido em 16/07/2012. Aprovado em 04/10/2012. 